\title{
Correction to: Hybrid Amplitude Control Antenna Array System for Energy Efficient W-CDMA Network with Adaptive Coverage and Capacity
}

\author{
Archiman Lahiry ${ }^{1}$ (D)
}

Published online: 12 January 2018

(C) Springer Science+Business Media, LLC, part of Springer Nature 2018

\section{Correction to: Wireless Pers Commun https://doi.org/10.1007/s11277-017-5032-3}

In the original publication, the reference to Fig. 41 in the second sentence in section 8.1 is incorrect. It should refer to Fig. 42. 